\title{
Time trends in respiratory symptoms in childhood over a 24 year period
}

\author{
P H Whincup, D G Cook, D P Strachan, O Papacosta
}

\begin{abstract}
Two cross sectional surveys, 24 years apart, using the same respiratory questionnaire, were carried out to examine changes in prevalence rates of cough, phlegm, and wheeze and to relate changes in wheeze to objective peak expiratory flow rates (PEFRs). The surveys were done in towns in southern and northern England and South Wales in schoolchildren aged 6.0-7.5 years; $n=1655$ in 1966 and $n=2323$ in 1990 . Parents reported on winter cough and winter phlegm (early morning or day/night) and wheeze; PEFRs were also measured.
\end{abstract}

The proportion of children reported as wheezing on most days or nights increased from $3.9 \%$ to $6 \cdot 1 \%$ (95\% confidence interval (CI) for increase -0.2 to 4.6 ), with a smaller increase in the prevalence of those who had ever wheezed. The proportion of children with day or night time cough increased from $21 \cdot 1 \%$ to $33.3 \%(95 \%$ CI for increase 3.8 to 20.6$)$ and the proportion with day or night time phlegm increased from $5.8 \%$ to $10.0 \%(95 \%$ CI for increase 0.4 to 8.0 ). Smaller increases in the prevalence of persistent cough (from $9.0 \%$ to $12.4 \%$ ) and persistent phlegm (from $2.4 \%$ to $3.5 \%$ ) were also observed, while morning cough and morning phlegm showed little change. The increases in cough and phlegm were apparent in subjects with and without a history of wheeze. Both absolute and proportional changes in symptom prevalence were generally greater in the north than in the south. Similar social class trends were seen in each survey. The mean difference in PEFR between subjects with and without wheeze was smaller in 1990 than in 1966, but this result could be influenced by a greater proportion of subjects receiving antiasthmatic treatment in the 1990 survey.

These apparent increases in the prevalence of persistent wheeze, day and night time cough and phlegm, occurring over a period during which outdoor air pollution levels have decreased substantially, deserve further investigation.

(Arch Dis Child 1993; 68: 729-734)

Department of Public

Royal Free Hospital and

School of Medicine,

London NW3 2PF

P H Whincup

O Papacosta

Department of Public Health Sciences, St George's Hospital Medical School, London

D G Cook

D P Strachan

Correspondence to:

Dr Whincup.

Accepted 25 January 1993 although earlier suggestions that asthma been substantiated. ${ }^{35}$ The increase in medical activity may reflect changes in the prevalence or severity of the disease. Alternatively, it may mortality is increasing in childhood ${ }^{4}$ have not reflect improvement in the recognition of the condition, or an increase in the use of asthma as a diagnostic label. Studies of the prevalence of asthmatic symptoms have produced conflicting results. While reviews of the findings of one off prevalence surveys have observed little consistent change in the prevalence of wheezing illness, ${ }^{6-8}$ serial surveys conducted in the same location with similar methodologies have generally supported the possibility of an increase in the prevalence of wheeze. ${ }^{-14}$ Several of these serial surveys also observed increases in the prevalence of asthma reported by parents that were substantially more marked than the increases in the prevalence of wheeze, ${ }^{9-13}$ suggesting the possibility of a considerable rise in the recognition and labelling of wheezing illness as asthma. However, in one recent survey the increases in wheezing and reported asthma were similar ${ }^{14}$ and in another the increase in prevalence of wheeze was greater in subjects without a diagnostic label than in subjects with one, ${ }^{12}$ suggesting that changes in the recognition and labelling of asthma do not provide a complete explanation for the increases in the prevalence of wheezing illness observed.

Despite the interest in changes in wheeze, little attention has been paid to time trends in other childhood respiratory symptoms, particularly cough and phlegm. This report describes changes in the prevalence of childhood respiratory symptoms between two surveys conducted in England and Wales in 1966 and 1990 using the same questions to inquire about wheeze, cough, and phlegm. Both surveys included measurements of peak expiratory flow rate (PEFR), providing an objective measure of respiratory function that can be used to address the validity of changes in reported symptom prevalence. ${ }^{15}$

\section{Subjects and methods}

SCHOOLCHILD CHEST HEALTH SURVEY (1966)

This survey was conducted in five urban and five rural areas of England and Wales, of which only the urban areas are included here. ${ }^{16}$ The five urban areas included two in southern England (Bristol and Reading), two in northern England (Bolton and Newcastle) and one in Wales (Merthyr Tydfil). Within each of these centres a random sample of local primary schools (stratified by district in the case of the largest towns) provided a sample of 500 children of each sex aged between 6 and 10 years who were invited to take part. The survey was conducted between September and November 1966.

\section{Questionnaire}

A questionnaire was sent to parents at the outset, 
requesting information on the child's respiratory symptoms and history of past respiratory illness (but not medications for respiratory illness). Father's occupation was used to define social class; no distinction was made between III nonmanual and III manual. A response rate of $97 \cdot 8 \%$ was obtained. Parents were asked the following questions about cough, phlegm, and wheeze:

- Does he/she usually cough first thing in the morning in winter? (yes/no)

- Does he/she usually cough during the day, or at night in winter? (yes/no)

If 'yes' (to either or both of these questions), does he/she cough like this on most days for as much as three months each year? (yes/no)

- Does he/she bring up any phlegm (spit) from the chest first thing in the morning in winter? (yes/no)

- Does he/she bring up any phlegm (spit) from the chest during the day or at night in the winter? (yes/no)

- If 'yes' (to either or both of these questions), does he/she bring up phlegm like this on most days for as much as three months each year? (yes/no)

Does this child's chest ever sound wheezy or whistling? (yes/no)

- If 'yes', does he/she get this on most days or nights of the year? (yes/no)

(The presence of cough or phlegm lasting for three months of the year is referred to as 'persistent cough' or 'persistent phlegm'.)

\section{Clinical measurements}

PEFR was measured using a Wright peak flow meter by a total of 30 school medical officers in different locations. Five measurements were made in each case; the mean of the last three readings was used in analysis. All measurement procedures were standardised and meters were centrally calibrated.

ratios for chronic obstructive pulmonary disease and allied conditions (ICD-9 490-496) in adults (men and women 35-74 years; 1982-6) for the district health authority populations relating to the towns studied in 1966 (Schoolchild Chest Health Survey) and in 1990 (Ten Towns Study). Source: Office of Population Censuses and Surveys.

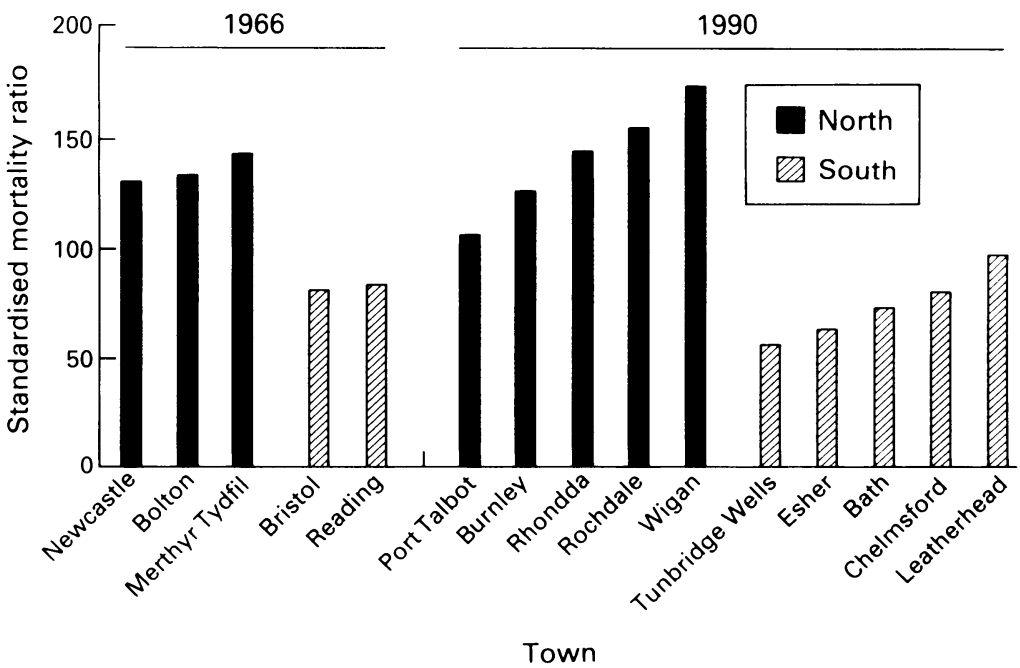

This study of blood pressure and respira function was conducted in 10 towns, selected on the basis of their size (population 50000 to 100000 ) and their current adult cardiovascular mortality rate. ${ }^{17}$ Five with exceptionally high cardiovascular mortality rates (Wigan, Port Talbot, Burnley, Rhondda, Rochdale) and five with exceptionally low rates (Esher, Chelmsford, Leatherhead, Bath, Tunbridge Wells) were included. Within each of these towns a stratified random sample of primary schools provided a sample of 550 children aged between 5 and 7 years who were invited to take part. The survey was conducted between January and July 1990 .

\section{Questionnaires}

Questionnaires were sent to the parents of all children who took part in the measurement survey and were returned for $68 \%$ of those invited. The questionnaire included precisely the same questions about cough, phlegm, and wheeze as those in the Schoolchild Chest Health Survey. In addition, parents were asked whether the child had ever had asthma, bronchitis, pneumonia, bronchiolitis, eczema, or hayfever and were asked to list all medications taken by the child; those used for the treatment of asthma were identified using a 1990 British National Formulary. Social class coding was based on the occupation of the father as in the 1966 survey, using the Registrar General's 1980 manual for social class coding. In order to ascertain the prevalence of respiratory illnesses in nonparticipants, a brief questionnaire was sent to all non-repondents in the last four towns surveyed, which included the same questions about named illnesses as in the main questionnaire. A response to this brief questionnaire was obtained from 259 of 612 subjects $(42 \%)$.

\section{Clinical measurements}

Measurements of respiratory function were made by one of a team of four research nurses. Three forced expiratory manoeuvres were carried out using a Vitalograph Compact pneumatochograph (Vitalograph Ltd); in accordance with American Thoracic Society recommendations, ${ }^{18}$ the peak expiratory flow measurement associated with the best forced expiratory volume in one second $\left(\mathrm{FEV}_{1}\right)+$ forced vital capacity (FVC) measurement was recorded

\section{STATISTICAL METHODS}

The results presented here are restricted to the age group common to the two studies, $6 \cdot 0$ to $7 \cdot 5$ years. No children in ethnic minority groups were included in the Schoolchild Chest Health Survey and results are therefore restricted to children of European origin throughout. Because the Ten Towns Study was entirely based in urban areas, results presented for the Schoolchild Chest Health Survey are restricted to the five urban areas and exclude rural locations. In order to ascertain the comparability of the towns included in the two surveys, their recent adult mortality experience for chronic obstructive pulmonary disease (ICD-9 490-496) is summarised for the years 1982-6 using standardised mortality ratios in the figure. In both study groups mortality rates are markedly higher in northern England and Wales than in the south; within each of these regions standardised 
Table 1 Prevalence rates (\%) of childhood respiratory symptoms in 1966 and 1990 surveys

\begin{tabular}{|c|c|c|c|c|c|c|}
\hline & 1966 & 1990 & Adjustment & $\begin{array}{l}\text { Increase } \\
(S E)\end{array}$ & $95 \% C I$ & $p$ Value \\
\hline Wheeze ever & $18 \cdot 3$ & $21 \cdot 8$ & $\begin{array}{l}\text { None } \\
\text { North-south }\end{array}$ & $\begin{array}{l}3.5(1.9) \\
3.7(2.0)\end{array}$ & $(-0.7$ to 8.0$)$ & $\begin{array}{l}0.09 \\
0.09\end{array}$ \\
\hline Wheeze most days or nights & 3.9 & $6 \cdot 1$ & $\begin{array}{l}\text { None } \\
\text { North-south }\end{array}$ & $\begin{array}{l}2 \cdot 2(1 \cdot 2) \\
2 \cdot 5(0 \cdot 8)\end{array}$ & $(0.8$ to 4.2$)$ & $\begin{array}{l}0.08 \\
0.007\end{array}$ \\
\hline Morning cough & $11 \cdot 2$ & $11 \cdot 3$ & $\begin{array}{l}\text { None } \\
\text { North-south }\end{array}$ & $\begin{array}{l}0.1(1.5) \\
0.4(1.2)\end{array}$ & $(-2 \cdot 2$ to $3 \cdot 0)$ & $\begin{array}{l}0.95 \\
0.72\end{array}$ \\
\hline Day-night cough & $21 \cdot 1$ & $33 \cdot 3$ & $\begin{array}{l}\text { None } \\
\text { North-south }\end{array}$ & $\begin{array}{l}12 \cdot 1(4 \cdot 2) \\
13 \cdot 2(2 \cdot 8)\end{array}$ & $(7 \cdot 1$ to $19 \cdot 3)$ & $\begin{array}{l}0.01 \\
0.0001\end{array}$ \\
\hline Persistent cough & $9 \cdot 0$ & $12 \cdot 4$ & $\begin{array}{l}\text { None } \\
\text { North-south }\end{array}$ & $\begin{array}{l}3.4(2.0) \\
3.8(1.8)\end{array}$ & $(-0.0$ to 7.6$)$ & $\begin{array}{l}0.11 \\
0.05\end{array}$ \\
\hline Morning phlegm & $5 \cdot 0$ & $5 \cdot 8$ & $\begin{array}{l}\text { None } \\
\text { North-south }\end{array}$ & $\begin{array}{l}0.9(1.1) \\
1.1(1.0)\end{array}$ & $(-1 \cdot 1$ to $3 \cdot 3)$ & $\begin{array}{l}0.47 \\
0.31\end{array}$ \\
\hline Day-night phlegm & $5 \cdot 8$ & $10 \cdot 0$ & $\begin{array}{l}\text { None } \\
\text { North-south }\end{array}$ & $\begin{array}{l}4 \cdot 2(1 \cdot 9) \\
4 \cdot 6(1 \cdot 5)\end{array}$ & (1.2 to 7.9$)$ & $\begin{array}{l}0.04 \\
0.01\end{array}$ \\
\hline Persistent phlegm & $2 \cdot 4$ & $3 \cdot 5$ & $\begin{array}{l}\text { None } \\
\text { North-south }\end{array}$ & $\begin{array}{l}1 \cdot 1(1.0) \\
1.3(0.9)\end{array}$ & $(-0.6$ to 3.2$)$ & $\begin{array}{l}0.30 \\
0.15\end{array}$ \\
\hline
\end{tabular}

Proportions and SE are based on town data, which are presented for each symptom without adjustment and with a north-south adjustment.

$\mathrm{CI}=$ confidence interval.

Table 2 Prevalence rates (\%) of childhood respiratory symptoms in 1966 and 1990 surveys by region

\begin{tabular}{|c|c|c|c|c|c|c|}
\hline & \multicolumn{3}{|l|}{ North } & \multicolumn{3}{|l|}{ South } \\
\hline & 1966 & 1990 & Increase $(S E)$ & 1966 & 1990 & Increase $(S E)$ \\
\hline $\begin{array}{l}\text { Wheeze ever } \\
\text { Wheeze most days or nights } \\
\text { Day-night cough } \\
\text { Persistent cough } \\
\text { Day-night phlegm } \\
\text { Persistent phlegm }\end{array}$ & $\begin{array}{r}17 \cdot 8 \\
5 \cdot 1 \\
22 \cdot 0 \\
8 \cdot 4 \\
6 \cdot 5 \\
2 \cdot 8\end{array}$ & $\begin{array}{r}23 \cdot 1 \\
7 \cdot 7 \\
40 \cdot 7 \\
15 \cdot 5 \\
12 \cdot 6 \\
4 \cdot 8\end{array}$ & $\begin{array}{r}5 \cdot 3(2 \cdot 6) \\
2 \cdot 6(1 \cdot 1) \\
18 \cdot 7(2 \cdot 1) \\
7 \cdot 1(1 \cdot 7) \\
6 \cdot 1(1 \cdot 3) \\
2 \cdot 0(1 \cdot 2)\end{array}$ & $\begin{array}{r}19 \cdot 0 \\
2 \cdot 1 \\
19 \cdot 8 \\
10 \cdot 0 \\
3 \cdot 9 \\
1 \cdot 7\end{array}$ & $\begin{array}{r}20 \cdot 5 \\
4 \cdot 5 \\
25 \cdot 8 \\
9 \cdot 4 \\
7 \cdot 5 \\
2 \cdot 2\end{array}$ & $\begin{array}{r}1 \cdot 5(3 \cdot 1) \\
2 \cdot 4(1 \cdot 2) \\
6 \cdot 0(4 \cdot 4) \\
-0 \cdot 6(2 \cdot 4) \\
2 \cdot 5(3 \cdot 0) \\
0 \cdot 5(1 \cdot 2)\end{array}$ \\
\hline
\end{tabular}

mortality ratios appear similar in the two studies. A similar comparison emerges if mortality rates at the time of the 1966 survey are examined.

The symptom analyses presented are based on towns, not on individual subjects. Such analyses allow the effect of random variation in town characteristics between studies to be taken into account. The only exceptions are the analyses for social class, which are based on individuals. Adjustment for the effect of age and sex between studies had no important effect on the results and has therefore been omitted; because the results were similar for boys and girls all results are presented for both sexes combined. Two sample $t$ tests were used to compare town prevalence rates in the two studies. Geographic differences in symptoms were allowed for by grouping towns into those in the south and those in the north (including Wales), using the conventional dividing line between the Bristol Channel and The Wash. Town prevalence rates were then regressed on two $0 / 1$ variables, one representing period, the other geographic location.

Analyses of PEFRs are based on individuals. Adjustment for age and height (fitted as continuous variables) and sex (fitted as a $0 / 1$ variable) was carried out using a standard linear regression technique (PROC GLM, SAS). Peak flow measurements were carried out using different techniques in 1966 and 1990 and are not directly comparable. Peak flow results (table 5) have therefore been presented as percentages of values in the non-wheezers within each study.

\section{Results}

The symptom prevalence results are based on 1655 children aged 6.0 to $7 \cdot 5$ years in the 1966 survey and 2323 children in the 1990 survey. The
Table 3 Prevalence rates (\%) of childhood respiratory symptoms in 1966 and 1990 surveys by father's social class

\begin{tabular}{|c|c|c|c|c|c|c|c|c|}
\hline \multirow{2}{*}{$\begin{array}{l}\text { Social } \\
\text { class }\end{array}$} & \multicolumn{2}{|l|}{ No } & \multicolumn{2}{|c|}{$\begin{array}{l}\text { Day-night } \\
\text { cough }\end{array}$} & \multicolumn{2}{|c|}{$\begin{array}{l}\text { Day-night } \\
\text { phlegm }\end{array}$} & \multicolumn{2}{|c|}{$\begin{array}{l}\text { Wheeze most } \\
\text { days/nights }\end{array}$} \\
\hline & 1966 & 1990 & 1966 & 1990 & 1966 & 1990 & 1966 & 1990 \\
\hline $\begin{array}{l}\text { II } \\
\text { III } \\
\text { IV } \\
\text { V }\end{array}$ & $\begin{array}{r}63 \\
156 \\
935 \\
248 \\
142\end{array}$ & $\begin{array}{r}176 \\
666 \\
1616 \\
224 \\
90\end{array}$ & $\begin{array}{l}12 \cdot 7 \\
14 \cdot 7 \\
20 \cdot 6 \\
25 \cdot 0 \\
24 \cdot 7\end{array}$ & $\begin{array}{l}20 \cdot 6 \\
26 \cdot 3 \\
34 \cdot 6 \\
39 \cdot 7 \\
52 \cdot 2\end{array}$ & $\begin{array}{l}1 \cdot 6 \\
2 \cdot 7 \\
6 \cdot 3 \\
6 \cdot 2 \\
9 \cdot 5\end{array}$ & $\begin{array}{r}4.1 \\
6.8 \\
10.7 \\
13.8 \\
15.6\end{array}$ & $\begin{array}{l}1 \cdot 6 \\
1 \cdot 3 \\
3 \cdot 5 \\
3 \cdot 8 \\
7 \cdot 2\end{array}$ & $\begin{array}{r}3.5 \\
3.0 \\
6.4 \\
4.9 \\
17.8\end{array}$ \\
\hline
\end{tabular}

proportion of children with each symptom in the 1966 and 1990 surveys is presented in table 1. Because of the marked difference in symptom prevalences between north and south (table 2) and the different balance of towns between the north and south in the two studies, results are presented both without and then with adjustment for north-south differences. Although the prevalence of 'wheeze ever' increased between 1966 and 1990, the proportional increase (19\%) was small. However, there was a striking proportional increase in the prevalence of 'wheeze on most days and nights' (56\%). 'Morning cough' and 'morning phlegm' showed little change but there were marked increases in the prevalence of 'day-night cough' and 'day-night phlegm', while 'persistent cough' and 'persistent phlegm' showed more modest increases. North-south standardisation accentuated both the size of the increases and their statistical significance levels in all cases.

\section{CHANGES IN GEOGRAPHIC AND SOCIAL} DISTRIBUTION OF SYMPTOMS

The distribution of respiratory symptoms between the north and south in the 1966 and 1990 survey is examined in table 2. Morning cough and morning phlegm, which showed little overall change between 1966 and 1990, have not been included in this table. In the 1966 survey wheeze on most days or nights, day-night phlegm and persistent phlegm had a greater prevalence in the north while the other three symptoms showed no marked north-south difference. In the 1990 survey, all six symptoms had higher prevalence rates in the north than the south. As a corollary, the absolute increases in prevalence rate between 1966 and 1990 were markedly greater in the north than in the south for all symptoms except wheeze on most days or nights; the difference in trend between the north and south achieved statistical significance $(p<0.05)$ for day-night cough and persistent cough. The social class distribution of the prevalence rates of day-night cough, day-night phlegm, and wheeze on most days or nights in the 1966 and 1990 surveys are presented in table 3. Each of the three symptoms showed a social class gradient in the 1966 survey, with all symptoms being more prevalent in the classes IV and V than in I and II. The social class gradient was weakest for day-night cough (twofold difference) and strongest for day-night phlegm (fivefold difference). In the 1990 survey, social class gradients of a similar direction and magnitude were observed for each symptom, implying that the proportionate increases in symptoms over 
Table 4 Prevalence rates (\%) of childhood respiratory symptoms in 1966 and 1990 surveys in non-wheezers

\begin{tabular}{|c|c|c|c|c|c|}
\hline & 1966 & 1990 & Adjustment & Increase $(S E)$ & $p$ Value \\
\hline Day-night cough & $13 \cdot 2$ & $23 \cdot 7$ & $\begin{array}{l}\text { None } \\
\text { North-south }\end{array}$ & $\begin{array}{l}10 \cdot 4 \\
11 \cdot 4(2 \cdot 8)\end{array}$ & 0.001 \\
\hline Persistent cough & $3 \cdot 3$ & $5 \cdot 4$ & $\begin{array}{l}\text { None } \\
\text { North-south }\end{array}$ & $\begin{array}{l}2 \cdot 2 \\
2 \cdot 5(1 \cdot 4)\end{array}$ & $0 \cdot 10$ \\
\hline Day-night phlegm & $2 \cdot 5$ & $5 \cdot 1$ & $\begin{array}{l}\text { None } \\
\text { North-south }\end{array}$ & $\begin{array}{l}2 \cdot 6 \\
2 \cdot 9(1 \cdot 2)\end{array}$ & 0.03 \\
\hline Persistent phlegm & 0.7 & 0.9 & $\begin{array}{l}\text { None } \\
\text { North-south }\end{array}$ & $\begin{array}{l}0.2 \\
0.3(0.4)\end{array}$ & 0.43 \\
\hline
\end{tabular}

Proportions and SE are based on town data, which are presented for each symptom without adjustment and with a north-south adjustment.

Table 5 Relationship between wheeze and PEFRs in 1966 and 1990 surveys

\begin{tabular}{|c|c|c|c|}
\hline & \multicolumn{3}{|c|}{ PEFR (\% of non-wheezers) } \\
\hline & $\begin{array}{l}\text { Non- } \\
\text { wheezers }\end{array}$ & $\begin{array}{l}\text { Wheeze ever } \\
\%(S E)\end{array}$ & $\begin{array}{l}\text { Wheeze most } \\
\text { days or nights } \\
\%(S E)\end{array}$ \\
\hline $\begin{array}{l}1966 \text { Survey }^{\star} \\
\text { All subjects }\end{array}$ & 100 & $95 \cdot 3(1 \cdot 4)$ & $90 \cdot 7(2 \cdot 5)$ \\
\hline $\begin{array}{l}1990 \text { Surveyt } \\
\text { All subjects }\end{array}$ & 100 & $97 \cdot 8(1 \cdot 3)$ & $95 \cdot 5(1 \cdot 9)$ \\
\hline $\begin{array}{l}\text { Subjects on antiasthmatic treatment excluded } \\
\quad(n=186)\end{array}$ & 100 & $98 \cdot 1(1 \cdot 5)$ & $91 \cdot 6(2 \cdot 5)$ \\
\hline
\end{tabular}

Wheeze categories in this analysis have been treated as mutually exclusive (that is subjects with wheeze most days or nights are excluded from the wheeze ever group). All analyses are adjusted for age, sex, and height.

$\star$ Subjects in 1966 survey were: 1312 non-wheezers, 211 with wheeze ever, 60 with wheeze on most days and nights.

tSubjects in 1990 survey were: 1668 non-wheezers, 300 with wheeze ever, 126 with wheeze on most days and nights. wheeze based on all subjects in the 1966 and 1990 studies is consistent with this possibility, with smaller proportional decreases in peak flow between non-wheezers and those with wheeze ever and wheeze most days or nights in 1990 than in 1966. However, the differences between the studies are not statistically significant either for wheeze ever $(p=0 \cdot 16)$ or for wheeze most days or nights $(p=0 \cdot 09)$. Moreover, this analysis does not take account of antiasthmatic treatment, which may have influenced the lung function of those reporting wheeze symptoms. Subjects receiving antiasthmatic treatment in the 1966 survey cannot be identified, although the results of contemporary surveys suggest that the prevalence would have been very low (of the order of $1 \%) .{ }^{11}$ If subjects receiving antiasthmatic treatment are excluded from the 1990 study $(n=186)$, the pattern of peak flow differentials observed in the remaining subjects is very close to that of the 1966 survey, particularly for subjects with wheeze most days or nights (table 5). Thus, when the effect of antiasthmatic treatment is taken into account, the severity of airway obstruction does not appear to have decreased with the increase in prevalence of wheeze.

\section{Discussion}

The comparisons of the prevalence of childhood respiratory symptoms in 1966 and 1990 described here showed a marked proportional increase in the prevalence of wheeze on most days or nights and a smaller proportional increase in the prevalence of those who had ever wheezed. The prevalences of cough or phlegm during the day or at night (and to a lesser extent persistent cough and persistent phlegm) had increased, while the prevalences of morning cough and morning phlegm were unchanged. The extent to which the changes observed can be explained by differences in the design and conduct of the 1966 and 1990 surveys must be considered. While the towns included in the two surveys were different, the adult respiratory mortality experience of the towns examined in the 1966 and 1990 surveys were similar in both cases (figure). Moreover, the study findings were not dependent on any individual town. The lower response rate observed in 1990 could in theory have had an important effect on the results. However, in a comparison of the reported prevalence of named respiratory and atopic illnesses in responders and non-responders in the 1990 survey, the prevalence of reported asthma was slightly lower in responders $(13 \cdot 1 \%)$ than in non-responders $(14.7 \%)$; a similar, slightly more marked, difference was observed for bronchitis $(7 \cdot 6 \%$ in responders and $10.4 \%$ in non-responders). These results suggest that the lower response rate observed in 1990 is unlikely to have accounted for the higher prevalence of symptoms in 1990. The difference in the time of year at which the two surveys were conducted is another potential source of bias. However, the effect of month of year on recall of symptoms within the 1990 survey between January and July was apparently small, suggesting that this factor is unlikely to explain the changes in symptom prevalence between 1966 and 1990. Although who had never wheezed. If the increase prevalence of asthma was due to greater parenta awareness, it might be expected that the proportional decrease in PEFR in wheezers would be smaller in 1990 than in 1966. The comparison between non-wheezers and both grades of 
the occurrence of an influenza epidemic immediately before the 1990 survey $^{20}$ might have accounted for a higher prevalence of acute respiratory symptoms, this should have had little effect on the response to the questions asked in the survey, especially those addressing persistent cough, phlegm, and wheeze.

\section{SECULAR CHANGES IN WHEEZE}

The prevalence rates for subjects reporting a history of wheeze ever in the 1990 survey $(21 \cdot 8 \%)$ are comparable with those of other recent surveys, ${ }^{101121}$ while those for wheeze on most days or nights $(6 \cdot 1 \%)$ are reasonably consistent with those of the most recent cohorts in the National Study of Health and Growth. ${ }^{12}$ The greater prevalence of persistent wheeze observed in the north and Wales is consistent with, although more marked than, the geographic variations in wheeze described in earlier reports. $^{22}$ The proportionate annual increase between 1966 and 1990 in the prevalence of wheeze on most days or nights $(1.9 \%)$ is rather smaller than the estimate of $5 \cdot 2 \%$ provided by the National Study of Health and Growth between 1973 and 1986, ${ }^{12}$ although the 95\% confidence limits on both estimates are wide. The annual increase is of a similar magnitude to that reported for wheeze in the past 12 months between 1978 and 1991 by Strachan and Anderson $(1 \cdot 1 \%),{ }^{13}$ although smaller than that reported by Hill et al for 1985 to $1988(3 \cdot 8 \%),{ }^{10}$ and by Burr et al for 1973-88 (3.7\%). ${ }^{11}$

There are several possible explanations for the increase in the prevalence of wheeze observed. While the change may reflect a true increase in the prevalence of asthma, increased parental awareness of childhood respiratory symptoms, or a lower threshold for reporting, are also potential explanations. A lower reporting threshold is likely to be a particular problem with the unquantified question about wheeze on most days or nights, which was used both here and elsewhere ${ }^{12}$ to identify children with persistent wheeze. However, the data on the relationship between wheeze symptoms and PEFR in the 1966 and 1990 surveys do not give strong support for this possibility. While the reduction in PEFR associated with wheeze ever and wheeze most days or nights was less marked in 1990 than in 1966 , this finding was strongly dependent on the inclusion of subjects on antiasthmatic treatment in the 1990 survey. The exclusion of subjects on treatment in the 1990 study produced a marked increase in the difference in PEFR between nonwheezers and those with wheeze on most days or nights, which became comparable with that in the 1966 survey. This finding does not support the possibility of a diminution in the severity of airway obstruction in subjects with wheeze on most days or nights. However, these results are difficult to interpret for two reasons. First, the effect of excluding those on treatment is seen only in the small group with wheeze most days and nights, and not in the very much larger group with wheeze ever. Second, it is not possible to exclude subjects on treatment in the 1966 survey in order to produce a comparable analysis. However, data from contemporary surveys suggest that the prevalence of antiasthmatic treatment would have been substantially lower in the 1966 survey, possibly of the order of $1 \%,{ }^{11}$ in which case removal of the group on treatment would have little effect. The results therefore suggest that the increase in the prevalence of wheeze is likely to be real, but emphasise the need for further longitudinal study in which symptom assessment is coupled with standardised measures of airway obstruction. They also point to the particular importance of taking into account changes in the prevalence of antiasthmatic treatment over time when interpreting the results.

\section{SECULAR CHANGES IN COUGH AND PHLEGM}

The results reported here suggest that the prevalence rates of cough or phlegm during the day or night and, to a lesser extent, persistent cough or phlegm, had increased between 1966 and 1990 , while the north-south gradient in cough and phlegm already apparent in the 1966 survey (and further substantiated by other surveys ${ }^{23}$ ), had become more marked in 1990 . An increase in the prevalence of asthma could in theory account for the increase in the prevalence of cough, ${ }^{19}$ even in the absence of wheeze. However, this seems an unlikely explanation for the observation. The proportional increase in cough was at least as great in non-wheezers as in those with a history of wheeze and did not follow the same geographic pattern as the increase in wheeze. Moreover, in the non-wheezers group there was no difference in the mean PEFR of those with or without cough (data not presented).

Other explanations for the observed increases in the prevalences of cough and phlegm are therefore required. Changes in parental awareness of respiratory symptoms, or in the parental threshold for symptom reporting, represent one possibility. However, the prevalences of morning cough and phlegm remained very consistent between 1966 and 1990, emphasising that any change in parental awareness or reporting threshold was being observed only for specific questions. An increase in the prevalence of lower respiratory tract infections (particularly acute bronchitis, bronchiolitis, or pneumonia) seems unlikely, given the consistent evidence from other sources that childhood morbidity and mortality from these conditions in childhood is declining. ${ }^{24}$ A further possibility is that the increase in the prevalence of symptoms is the result of bronchial irritation from non-infective causes, which could have included cigarette smoke and atmospheric or domestic air pollution. Active smoking seems an unlikely explanation in 6-7 year olds, a conclusion that is supported by the results of salivary cotinine analyses in the 1990 survey, suggesting that active smoking rates were extremely low (M J Jarvis, C Feyerabend, personal communication). Earlier studies have suggested that passive smoking, particularly resulting from parental smoking, is an important cause of childhood respiratory morbidity. ${ }^{25}$ Although no systematic data on changes in the prevalence of parental smoking are available, the prevalence of adult cigarette smoking has fallen steadily since the 
end of the 1960s, although marked regional variations in smoking prevalence remain. ${ }^{26}$

Atmospheric air pollution from sulphur dioxide and smoke, implicated as causes of childhood respiratory morbidity by earlier investigators, ${ }^{27}$ fell markedly following the introduction of the Clean Air Acts. ${ }^{29}$ Our observation that the falls in the levels of these pollutants have not been paralleled by reductions in the prevalence of respiratory symptoms in childhood is consistent with those of longitudinal studies conducted in the $1970 \mathrm{~s}^{30}$ and with the findings of other point prevalence surveys conducted between the 1960 s and $1980 \mathrm{~s}^{31-34}$ Increases in concentrations of other atmospheric pollutants, particularly oxides of nitrogen, have been observed. ${ }^{35}$ However, the contribution of atmospheric levels of these factors to childhood respiratory morbidity in childhood has still to be established. Despite earlier suggestions that nitrogen dioxide produced by gas cookers might be an important domestic cause of childhood respiratory morbidity, ${ }^{36}$ subsequent reports suggested that the effects were likely to be very small. ${ }^{37}$ The striking increases in the prevalence of childhood cough and phlegm observed here require further substantiation before more detailed investigations are carried out to establish the causes.

The Ten Towns Study was supported by project grants from the Medical Research Council and the Coronary Artery Disease Research Association (CORDA). Olia Papacosta was supported by the Chest, Heart and Stroke Association. We thank the members the Chest, Heart and Stroke Association. We thank the members of the field study team (Jenny Ashdown RGN, Wendy Cumper RGN, Sally Hirons RGN, Sharon Keegan RGN, and Vivienne Howse) and the education authorities, schools, parents, and children for their cooperation. The analysis of data from the Schoolchild Chest Health Study was made possible by the cooperation of Professor J R T Colley
Research Council data archive.

1 Fleming DM, Crombie DL. Prevalence of asthma and hay fever in England and Wales. $B M F$ 1987; 294: 279-83.

2 Anderson HR, Bailey P, West S. Trends in the hospital care of acute childhood asthma 1970-8: a regional study. $B M$ 1980; 281: $1191-4$

3 Alderson $M$. Trends in morbidity and mortality from asthma. Population Trends 1987; 49: 18-23.

4 Burney PGJ. Asthma mortality in England and Wales: evidence for a further increase, 1974-84. Lancet 1986; ii: 323-6.

5 Anderson HR, Strachan DP. Asthma mortality in England and Wales. L ancet 1991; 337: 1357.

6 Anderson HR. Is the prevalence of asthma changing? Arch Dis Child 1989; 64: 172-5.

7 Hay IFC, Higginbottam TW. Has the management of asthma improved? Lancet 1987; ii: 609-11.

8 Hill R, Tattersfield AE. Asthma in children: a comparison of community surveys in the UK. Thorax 1988; 43: 258-9.

9 Smith JM. The prevalence of asthma and wheezing in children. British Fourmal of Diseases of the Chest 1976; 70: 73-7.

10 Hill R, Williams J, Tattersfield A, Britton J. Change in use of asthma as a diagnostic label for wheezing illness in schoolchildren. BMF 1989; 299: 898.
11 Burr ML, Butland BK, King S, Vaughan-Williams E. Changes in asthma prevalence two surveys 15 years apart. Arch Dis Child 1989; 64: 1452-6.

12 Burney PGJ, Chinn S, Rona RJ. Has the prevalence of asthma increased in children? Evidence from the National Study of increased in children? Evidence fMF 1990; 300: 1306-10.

13 Strachan DP, Anderson HR. Trends in hospital admission rates for asthma in children. BMF 1992; 304: 819-20.

14 Ninan TK, Russell G. Respiratory symptoms and atopy in Aberdeen schoolchildren: evidence from two surveys 25 years apart. BMF 1992; 304: 873-5.

15 Britton JR. Asthma's changing prevalence. BMF 1992; 304: 857-8.

16 Colley JRT, Reid DD. Urban and social origins of childhood bronchitis in England and Wales. BMF 1970; ii: 213-7.

17 Whincup PH, Cook DG, Papacosta O, Walker M. Childhood blood pressure, body build and birthweight: geographic loodions with cardiovascular mortality. 7 Epidemiol Community Health 1992; 46: 396-402.

18 American Thoracic Society. Snowbird workshop on standardization of spirometry. Am Rev Respir Dis 1979; 119: 831-8.

19 Cloutier MM, Loughlin EM. Chronic cough in children: a manifestation of airway hyperreactivity. Pediatrics 1981; 67: 6-12.

20 Ashley J, Smith T, Dunnell K. Deaths in Great Britain associated with the influenza epidemic of 1989/90. Population Trends 1991; 65: 16-23.

21 Clifford RD, Radford M, Howell JB, Holgate ST. Prevalence of respiratory symptoms among 7 and 11 year-old schoolchildren and associations with asthma. Arch Dis Child 1989; 64: 1118-25.

22 Strachan DP, Golding J, Anderson HR. Regional variations in wheezing illness in British children: effect of migration wheezing illness in British children: effect of migration 44: 231-6.

23 Yarnell JWG, St Leger AS. Respiratory morbidity and lung function in schoolchildren aged 7 to 11 years in South Wales function in schoolchildren aged 7 to 11 years in Sout
and the west of England. Thorax 1981; 36: 842-6.

24 Anderson HR. Respiratory disease in childhood. Br Med Bull 1986; 42: 167-71.

25 Yarnell JWG, St Leger AS. Respiratory illness, maternal smoking habit and lung function in children. British fourna of Diseases of the Chest 1979; 73: 230-6.

26 Office of Population Censuses and Surveys. General household survey 1988. London: HMSO, 1988. (Series GHS, No 19. .)

27 Douglas JWB, Waller RE. Air pollution and respiratory ing Medicine 1967; 21: 7-16.

28 Lunn JE, Knowleden J, Handyside AJ. Patterns of respiratory illness in Sheffield infant schoolchildren. British fournal of Preventive and Social Medicine 1967; 21: 7-16.

29 Warren Spring Laboratory. National survey of smoke and sulphur dioxide April 1976-March 1977. London: Department of Industry and Trade, 1978.

30 Melia RJW, Florey C du V, Chinn S. Respiratory illness in British schoolchildren and atmospheric smoke and sulphur dioxide 1973-7. II: Longitudinal findings. $\mathcal{f}$ Epidemiol Community Health 1981 ; 35: 161-7.

31 Holland WW, Elliot A. Cigarette smoking, respiratory symptoms and antismoking propaganda. Lancet $1968 ; \mathrm{i}: 41-3$.

32 Bewley BR, Halil T, Snaith AH. Smoking by primary schoolchildren. Prevalence and associated respiratory symp27: $150-3$.

33 Rona RJ, Florey C du V. National study of health and growth: respiratory symptoms and height in primary school children. Int f Epidemiol 1980; 9: 35-43.

34 Johnston IDA, Bland JM, Anderson HR. Ethnic variation in respiratory morbidity and lung function in childhood Thorax 1987; 42: 542-8.

35 Building Effects Review Group Report. Trends in air pollution emissions and air quality in the United Kingdom. Building effects review group report. The effects of acid deposition on buildings and building materials in the UK. London: HMSO, 1989: 21-33.

36 Melia RJW, Florey C du V, Chinn S. The relation between respiratory illness in primary schoolchildren and the use of respiratory illness in primary schoolchildren and the use of gas for cooking. 1. Result

37 Melia RJW, Florey C du V, Morris RW, et al. Childhood respiratory illness and the home environment. II. Association between respiratory illness and nitrogen dioxide, temperature and relative humidity. Int $\mathcal{F}$ Epidemiol 1982; 11 164-9. 